\title{
Novel Measure of Acetabular Cup Inclination and Anteversion During Total Hip Arthroplasty
}

\author{
William L Walter', Neri A Baker $\mathbb{D}^{2}$, Daniel Marsden-Jones ${ }^{2}$, Ameneh Sadeghpour ${ }^{2}$ \\ 'Orthopaedics and Traumatic Surgery, University of Sydney, Sydney, New South Wales, Australia; ${ }^{2}$ Innovation Department, Navbit, Sydney, New \\ South Wales, Australia \\ Correspondence: William L Walter, Tel +6I 29160 6662, Email bill.walter@hipknee.com.au
}

\begin{abstract}
Purpose: The purposes of the present research were to assess the accuracy and usability of the inertial navigation system (INS).
Materials and Methods: The accuracy of the device navigation subsystem was assessed using benchtop testing. The usability was assessed through simulated use with surgeons. These results were compared to recent cadaveric results for the same system.

Results: The navigation subsystem had an overall mean absolute error of $1.21^{\circ}$ and a maximum absolute error across all devices of $4.79^{\circ}$. The device was found to be usable and to add an estimated 7 minutes to surgery time.

Conclusion: The INS uses a novel approach to provide the surgeon with accurate and fast acetabular cup inclination and anteversion angles during THA.

Keywords: THA, navigation, imageless, accurate, inertial, intraoperative

\section{Plain Language Summary}

Total hip arthroplasty (THA) is a well-established and effective surgical treatment for hip arthritis and is generally associated with positive outcomes. Computer navigation in THA can improve the accuracy of acetabular cup component placement, thereby improving patient outcomes and reducing revision surgeries, and yet usage remains very low. Issues affecting surgeon uptake include concerns about accuracy and complexity: devices that offer both accuracy and usability may increase the uptake of navigation. A new inertial navigation system (Navbit Sprint ${ }^{\circledR}$ ) has been developed to provide the surgeon simply and accurately with real-time inclination and anteversion angles. This palm-sized, surgeon-controlled navigation tool uses novel technology, including gyroscopes and accelerometers, and uses a novel registration process, which does not rely on patient landmarks. The resulting palm-sized device is used in the sterile field and does not require an external computer or other positioning equipment.
\end{abstract}

\section{Introduction}

Total hip arthroplasty (THA) is a well-established and effective surgical treatment for hip arthritis and is generally associated with positive outcomes relating to stability, durability, range of motion, and rehabilitation. ${ }^{1}$ However, THA has also been associated with adverse outcomes, potentially leading to revision surgery if conservative management is unsuccessful. ${ }^{2-4}$ Specifically, malpositioning of the acetabular cup has been associated with adverse outcomes, with the consequences including reduced range of motion, ${ }^{5-7}$ increased risk of dislocation, ${ }^{8,9}$ increased component wear, ${ }^{10}$ increased impingement, ${ }^{5,6}$ increased pain, and a resultant higher rate of revision. ${ }^{11}$ In fact, it has been suggested that $48 \%$ of avoidable revision THAs were the result of malpositioning of the acetabular cup. ${ }^{11}$ Improving acetabular cup orientation may, therefore, reduce adverse outcomes.

Compared with conventional freehand techniques, computer navigation improves the positioning of the acetabular cup and is associated with reduced rates of dislocation and revision. Navigation is any tool that provides the surgeon with intraoperative information about a component's position relative to patient anatomy. ${ }^{12}$ Based on whether intraoperative imaging is used, computer navigation is designated as imageless or image-based. ${ }^{12}$ Multiple systematic reviews and meta-analyses on THA have concluded that computer navigation improves the precision of acetabular cup positioning, 
compared with conventional freehand techniques, by reducing the number of outliers from the target alignment window. ${ }^{13-15}$ In addition, two reviews of healthcare data found that navigation was associated with lower rates of revision. In a review of 269,848 THAs in Australia, the cumulative rate of revision at 10 years due to dislocation was significantly lower with navigation $(0.4 \%)$ than without navigation $(0.8 \%) .{ }^{16}$ Similarly, a review of 803,732 THAs in the US found significantly lower dislocation and aseptic acetabular revision rates with navigation $(1.0 \%, 1.0 \%)$ than without navigation $(1.7 \%, 1.6 \%)$, respectively. ${ }^{17}$ These results combine to suggest that computer navigation enables more precise orientation of the acetabular cup, with associated lower rates of dislocation and revision.

Despite this evidence of improved acetabular cup orientation with navigation, navigation is not common in THA, which raises the question of why. Based on healthcare data, recent navigation rates are $1.8 \%$ in the $\mathrm{US}^{17}$ and $4.4 \%$ in Australia. ${ }^{16}$ In deciding whether to use navigation, a surgeon may consider the accuracy of the navigation and the time or complexity that navigation adds to surgery. While there is evidence that surgery time is significantly increased using computer navigation, ${ }^{14}$ there appears to be a distinction: Image-based navigation tends to increase preparation and surgery times, whereas imageless methods decrease or do not significantly change surgery time. ${ }^{12,18,19}$ However, this speed-related advantage of imageless over image-based methods has been diminished by mixed accuracy results. While one meta-analysis found that imageless computer navigation improved the accuracy of the anteversion and inclination angles of the acetabular cup, ${ }^{20}$ other reviews found that accuracy was poor with imageless navigation, likely arising from pelvic tilt and unreliable pelvic registration. ${ }^{21-23}$ Therefore, navigation systems that combine the speed and simplicity of imageless systems with the consistent accuracy of image-based systems may offer surgeons a feasible option.

The inertial navigation system in the present study (INS, Navbit Sprint ${ }^{\circledR}$ ) advances the state-of-the-art in hip navigation through using inertial sensors and a table tilt method for patient registration. Due to this novel approach, the device does not require an external computer or other positioning equipment. In fact, the main device is palm-sized, and the entire system is contained in a small, sterile package. Therefore, the entire system is used in the sterile field, removing the need for the surgical team to interact with a system outside of the sterile field. The present study assesses the accuracy and usability of this INS. An existing study assessed the accuracy of the INS device and registration process through surgeons performing normal surgical workflows on cadavers in a representative environment. ${ }^{24}$ With 6 surgeons performing a total of 12 full procedures on 6 cadavers, half using the direct anterior approach and half using the lateral approach, the INS measurements of the inclination and anteversion angles of the final cup orientation were compared to those calculated from a post-operative computed tomography (CT) scan for each hip. The mean of the absolute difference in inclination was $1.88^{\circ}\left(S D=1.37^{\circ}\right)$, and in anteversion was $3.70^{\circ}\left(S D=2.81^{\circ}\right)$. These results suggested very accurate performance using the device and the table tilt method of patient registration. The present study further assessed the INS by determining the accuracy that is possible using the inertial sensor technology (isolated from the broader surgical process) and the usability of the INS within the surgical process.

\section{Materials and Methods}

\section{Device Description and Technology}

The INS is a compact, surgeon-controlled guidance tool that has regulatory approval for use in the US, Europe, and Australia. Provided sterile, the system is single-use and disposable. Using a palm-sized computer module containing inertial sensors, including gyroscopes and accelerometers, the INS generates real-time inclination and anteversion angles, according to the radiographic definitions. ${ }^{25}$ These angles are displayed on an integrated graphical user interface (Figure 1) and are used to guide acetabular cup implantation.

The registration of a pelvic coordinate system is fundamental to the operation of an imageless navigation system such as the INS. Such a coordinate system acts as a reference frame based on the patient's rigid anatomy, against which component orientations can be measured and reported. Existing imageless hip navigation systems use a variety of registration methods; for most devices, the reference is the anterior pelvic plane (APP) and the registration relies on locating anatomical landmarks. ${ }^{26-31}$ These anatomical landmarks can be difficult and time-consuming to locate particularly if patients are obese or in a lateral position - and incorrect location leads to inaccurate navigation. ${ }^{27}$ Rather than using anatomical landmarks to define the APP, the INS uses the patient's position on the table during 


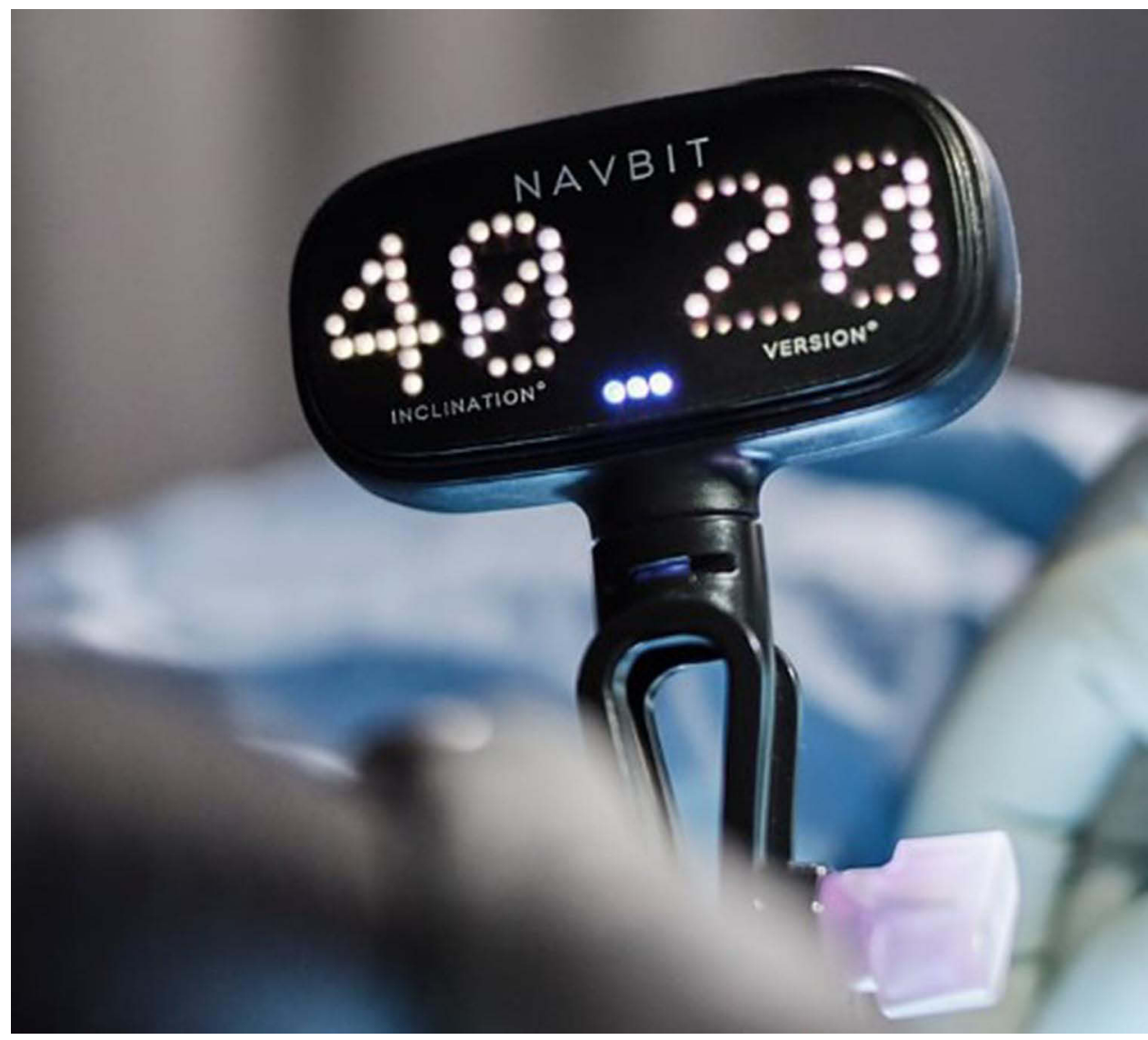

Figure I INS graphical user interface.

registration to define a functional pelvic reference system. Registration involves attaching the device (Figure $2 \mathrm{~A}$ ) to pelvic bone pins (Figure 2D) via a device mount (Figure 2C) and tilting the operating table. When the operating table is level, the device acquires the axis of gravity. Through the tilting of the operating table to the left and right, the device acquires the longitudinal axis of the patient. The acquisition of these axes enables the definition of a functional pelvic reference system for the patient. When the device is subsequently attached to the introducer/impactor via an impactor fitting (Figure 2B), the device displays the inclination and anteversion angles of the introducer/impactor (and, therefore, of the acetabular cup) relative to the reference system.

\section{Surgical Technique}

The INS integrates into the normal workflow for both conventional and minimally invasive surgery. After the patient is prepared for surgery, the package containing the sterile device is opened and left on a level surface while it activates and self-calibrates (Figure 3). The first bone pin is inserted into the ipsilateral or contralateral pelvis. Using the device mount as a guide, the second bone pin is inserted, and the device mount is then tightened securely (Figure 4). The impactor fitting is securely attached to the impactor (Figure 5) on a surface that is parallel to the impactor shaft axis. Before registration, the patient is aligned appropriately on a level operating table (Figure 6). The device is docked to the device mount, and registration occurs through a brief process of tilting the operating table. During this process, the table tilts approximately $10^{\circ}$ to each side, and the patient must remain correctly aligned with the table. Once registered, the device can be attached to the impactor fitting to provide the angle measurements. After registration, if the patient moves (for example, due to reaming or impaction), the device must be reattached to the device mount to regain the reference system. Then, the device may be transferred to the impactor fitting to provide further measurements. 


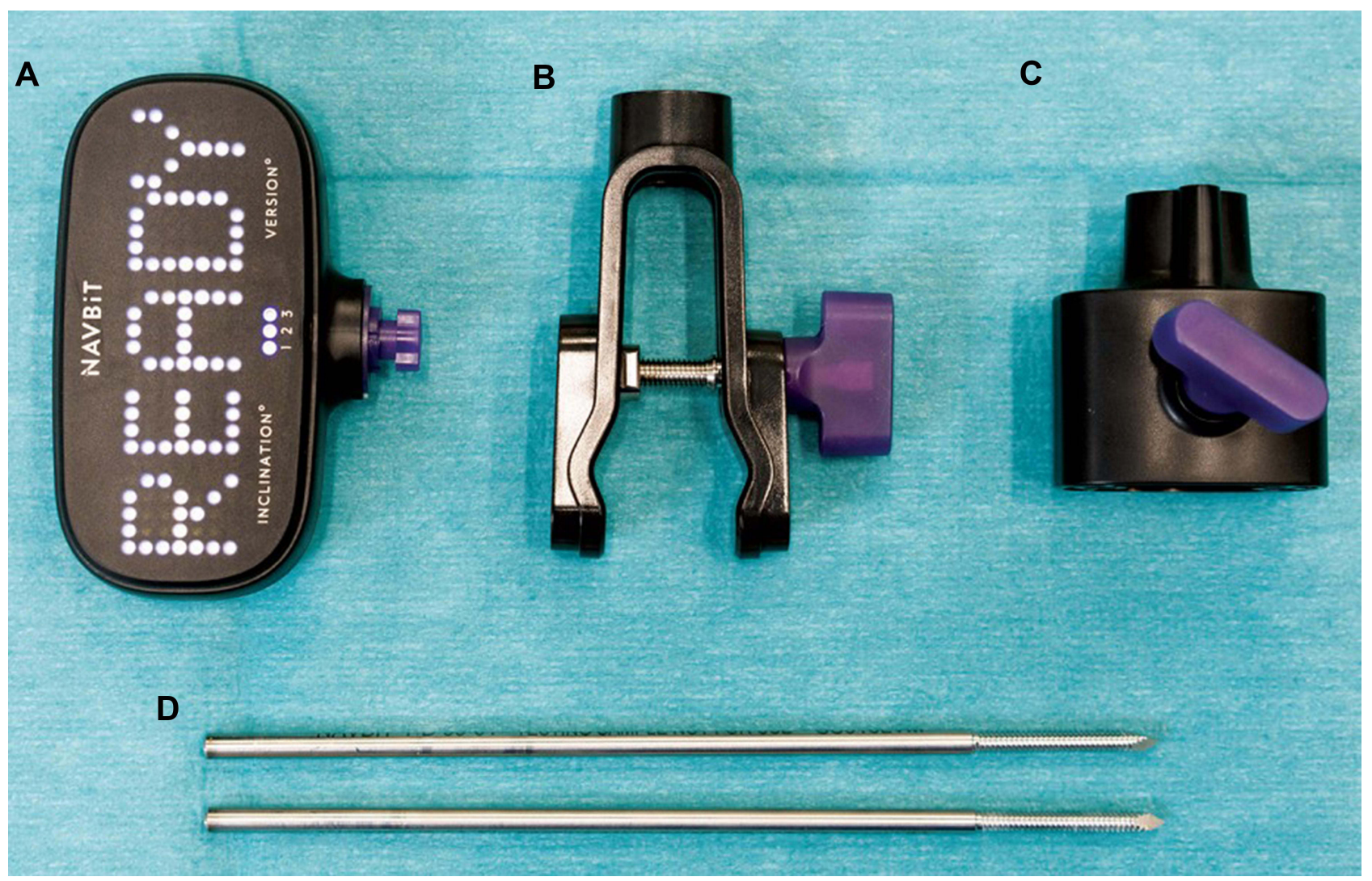

Figure 2 INS components.

Notes: The INS includes a device (A), impactor fitting (B), device mount (C), pelvic bone pins (D).

\section{Bench Testing of Measurement Accuracy Apparatus}

The measurement accuracy of the inertial tracking subsystem in the INS was evaluated using a precise phantom model, shown in Figure 7. On this phantom model, the base positions represented the inclination angles, and the fan positions represented the anteversion angles. Each combination of baseplate and fan position, therefore, represented a known 3D orientation. Radiographic inclination was represented by rotation around the base. Radiographic anteversion was represented by rotation around the fan. These base and fan positions were verified to within $\pm 0.6 \mu \mathrm{m}$ using a highprecision coordinate measuring machine (CMM). This resulted in known radiographic inclination and anteversion angles at each position, provided in Table 1. Prior to use, the phantom model was levelled to within $0.01^{\circ}$ using an inclinometer. Thus, the phantom model could be used as a precise standard for inclination and anteversion angles.

\section{Procedure}

A single INS device calibration, which was representative of the in-surgery registration process, was performed once per device prior to all measurements. To assess orientation accuracy, each of 5 INS devices was tested at 7 fan positions for each of 9 base positions (Figure 8A and B). To assess reliability, every measurement was repeated by rotating the device around the shaft, but perpendicular to the shaft, at 4 intervals of approximately $90^{\circ}$, designated as north, west, east, and south (Figure 8C). Two positions were excluded because of obstruction by the phantom. Therefore, there were 250 measurements per device. The devices were docked in the home position on the device mount (Figure 7C) between measurements. Data from the devices were collected via a Bluetooth Low Energy connection. The verified angles of the phantom, provided in Table 1, were taken as the true angles. Therefore, for each orientation, the errors in INS inclination and anteversion angles were calculated as the difference between the angle reported by the device and the verified angle of the phantom. 


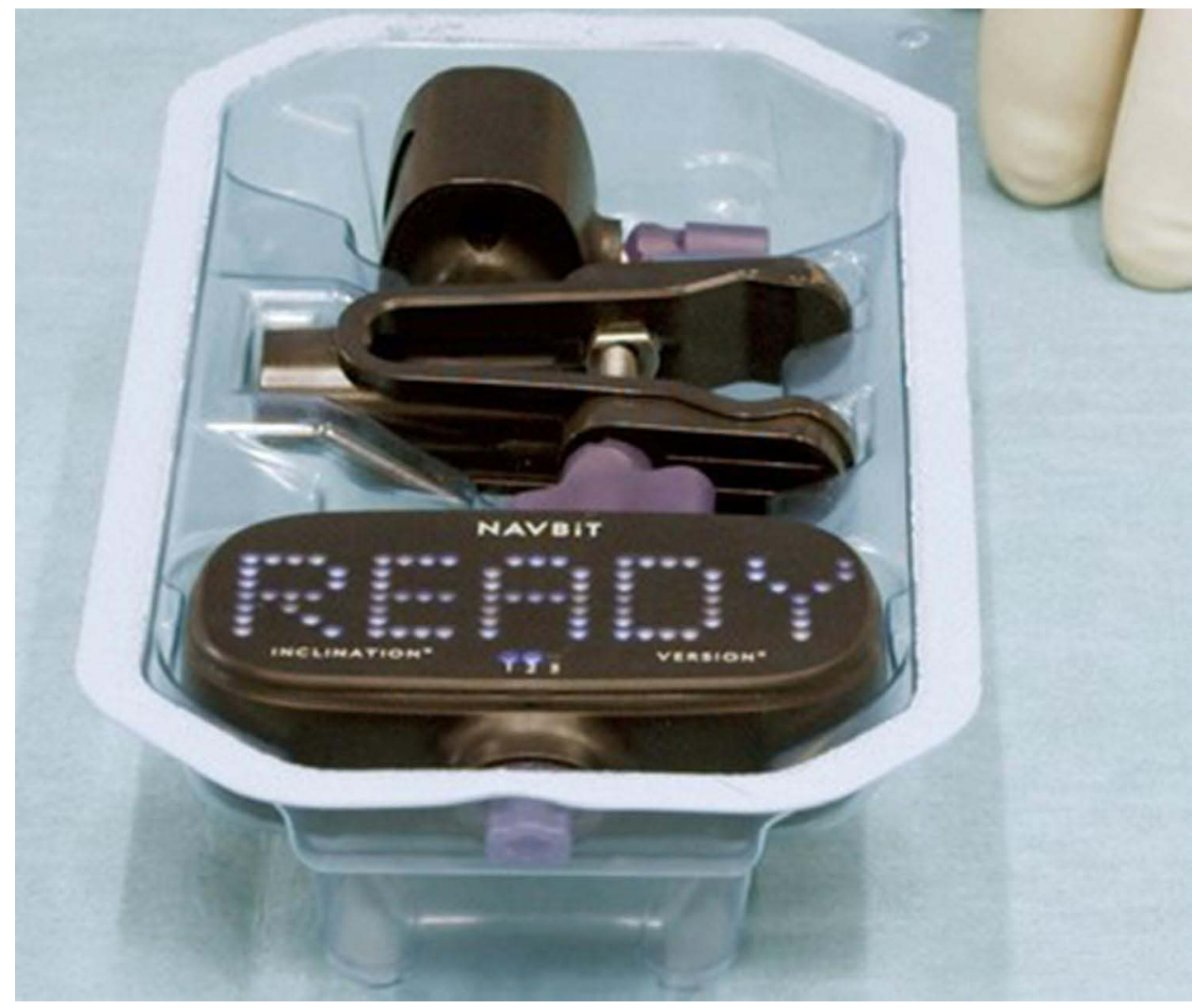

Figure 3 Device activation.

\section{Simulated Use Testing of Usability Apparatus}

Prior to the simulated use, the surgeons were trained via an instructional video that simulated the training typically provided by a sales representative. Surgery was simulated using Sawbones pelvic models in a surgical environment.

\section{Procedure}

The 15 study participants were orthopaedic surgeons. Most participants complete a low volume of hip arthroplasty procedures every year: 8 perform fewer than 50, 4 perform 50 to 100, and 3 perform more than 100. Eight participants had previously used a navigation product during hip arthroplasty. For these eight, the average number of navigated hip arthroplasty procedures in the preceding 12 months was $34.00(\mathrm{SD}=32.51)$ and ranged from 3 to 100 .

The INS device was validated according to the requirements of IEC 62366-1:2015 Medical devices - Application of usability engineering to medical devices. The test protocol simulated activities that are critical to the safe operation of the device:

- Identifying the correct Navbit Sprint for both supine and lateral patient registrations.

- Correctly aligning the patient on the operating table for pelvic registration for both lateral and supine patient registrations.

- Correctly establishing pelvic fixation.

- Correctly completing pelvic registration using the table tilt method.

- Correctly reading the angles of inclination and anteversion.

- Correctly assembling the impactor fitting, both to an offset impactor and to a straight impactor.

- Completing the system checking procedure. 


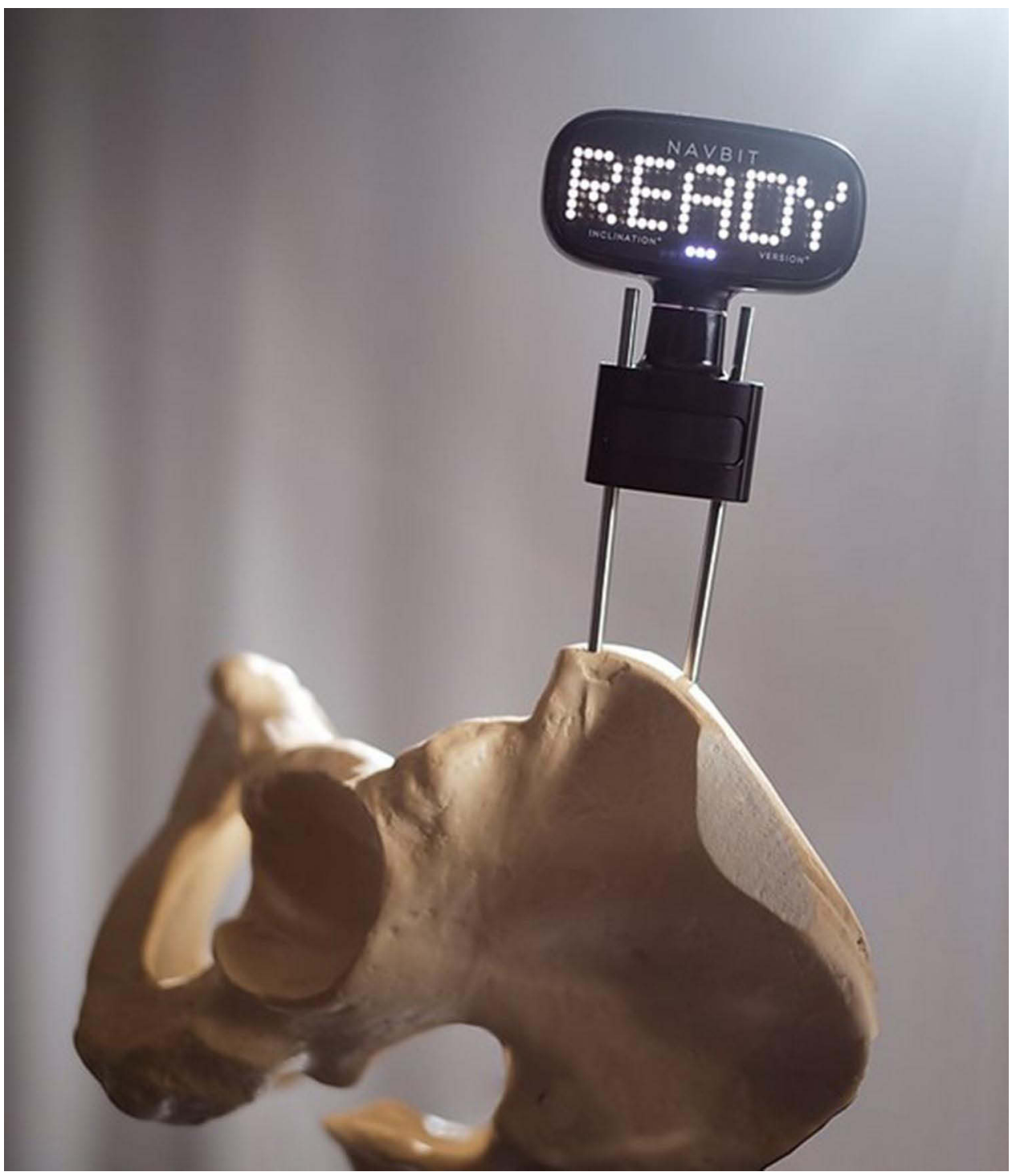

Figure 4 Device interface with pelvis.

Notes: The device is attached to the device mount. The bone pins attach the device mount to the pelvis.

- Understanding that a gel pad, sandbag, or rolled towel must not be put under the patient's buttocks during pelvic registration.

- Understanding when the Navbit Sprint is contraindicated.

In addition, a standard system usability scale was used: overall, how easy did you find the product to use? $(0=$ Not easy at all; 5 = Okay; $10=$ Very easy). After the simulation, participants were also asked: how many minutes do you think using the product would add to surgery time?

\section{Results}

\section{Bench Testing of Measurement Accuracy}

For each of the 250 orientations per device, the error was calculated as the difference between the verified angle of the phantom and the measurement reported by the device. The statistics for each device were calculated using the absolute values of the 250 error results. The statistics are provided in Table 2 and visualized in Figure 9. The devices had an overall mean absolute error of $1.21^{\circ}$ and a maximum absolute error across all devices of $4.79^{\circ}$. 


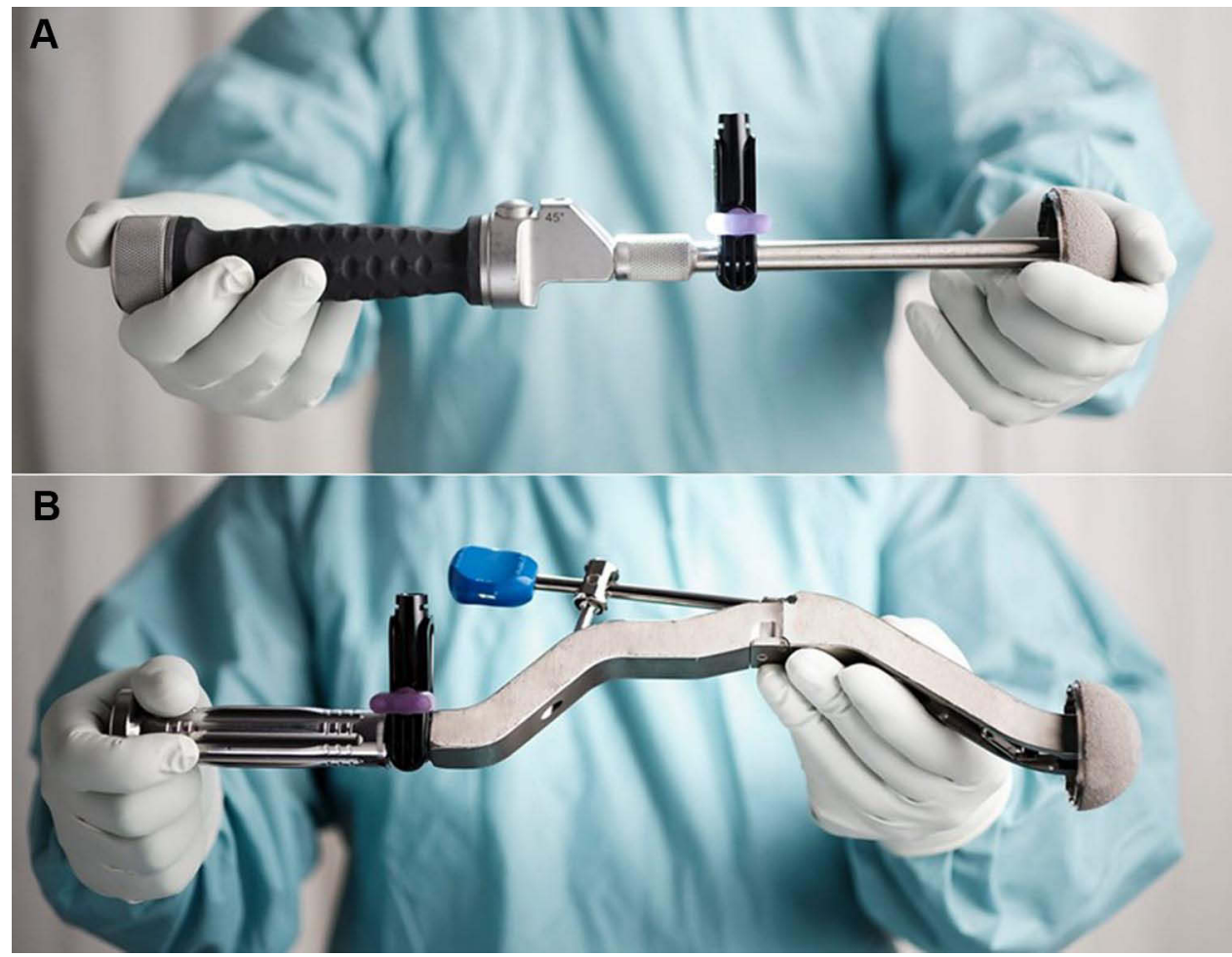

Figure 5 Device interface with impactor.

Notes: The device is attached to the impactor fitting, which in turn is attached to the impactor. The device may be attached to a straight impactor (A) or an offset impactor (B). The device is not indicated for use on a reamer.

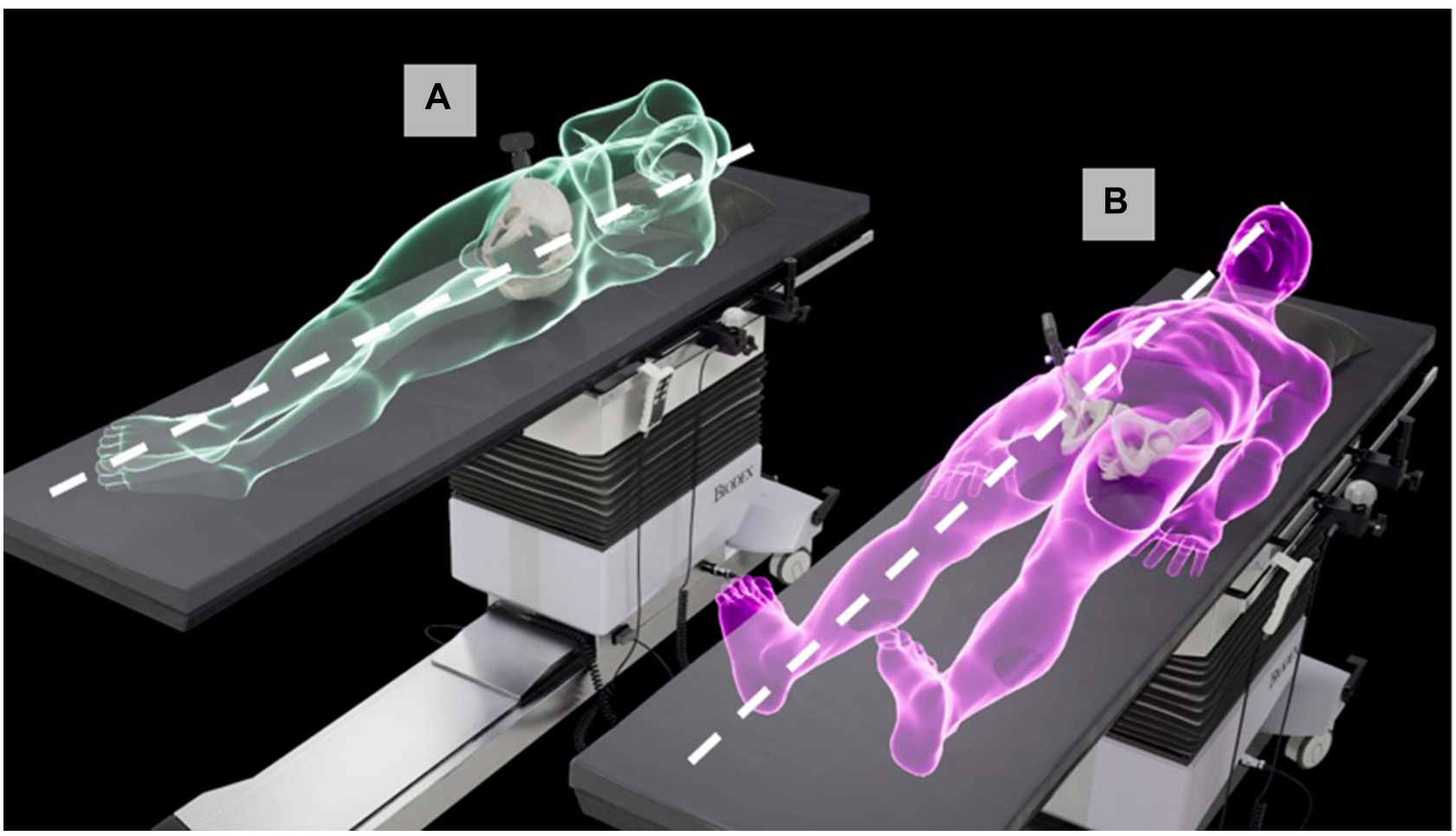

Figure 6 Patient position for registration.

Notes: The patient may be registered in the lateral (A) or supine (B) position for registration. In the lateral position, the left and right anterior superior iliac spines (ASIS) should be vertically aligned and the legs should be on top of each other. A pillow between the knees is recommended to assist in keeping the pelvis in a neutral position. The spine should be in a neutral position and should be parallel to the long axis of the operating table. In the supine position, the patient should be centered and parallel to the long axis of the operating table. 


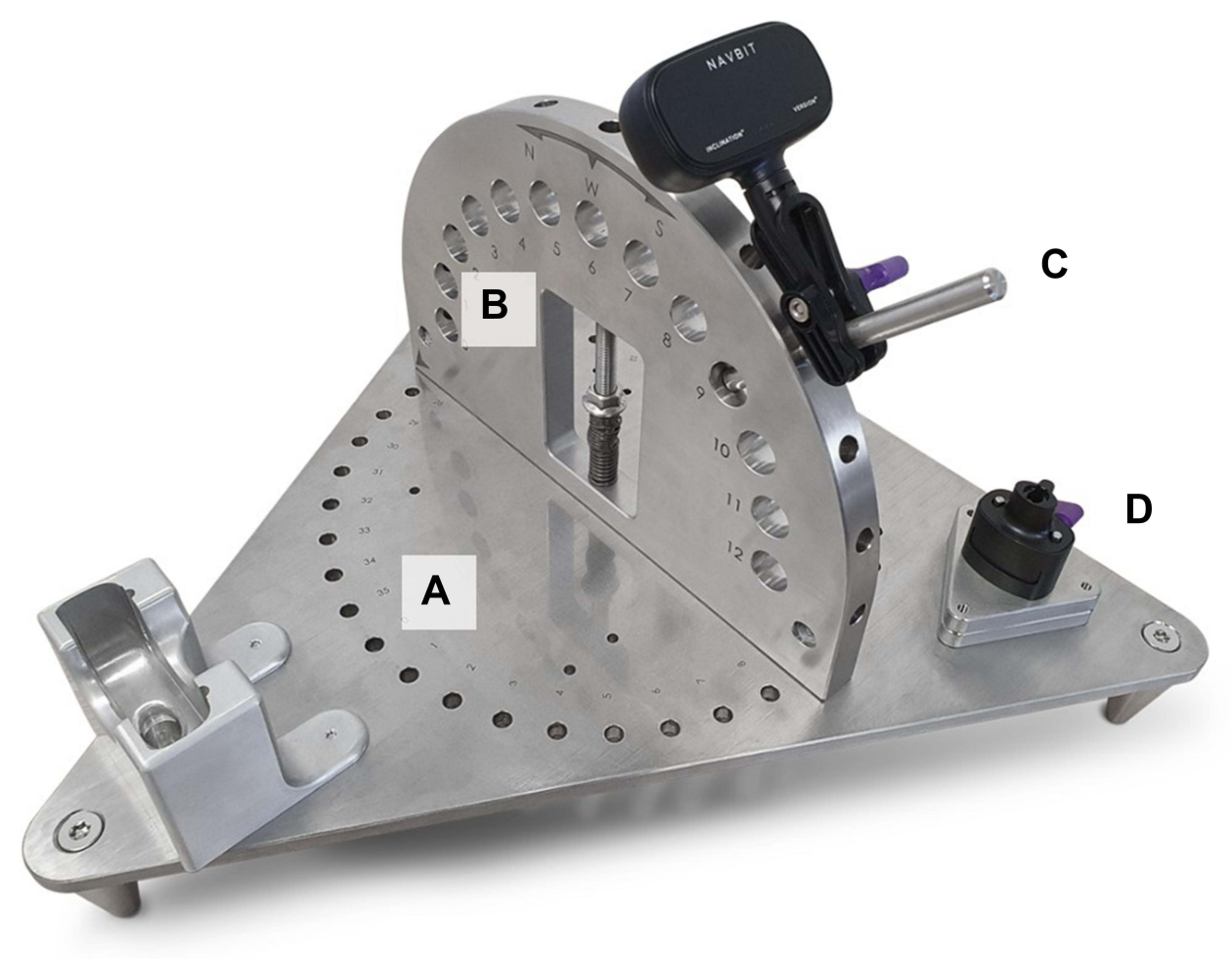

Figure 7 Phantom model.

Notes: Each calibrated location is a unique combination of base position $(\mathbf{A})$, fan position $(\mathbf{B})$, and shaft position $(\mathbf{C})$. The device may be attached to the shaft (C) or the device mount (D).

\section{Simulated Use Testing of Usability}

All participants were able to successfully complete all tasks in $99 \%$ of cases. There were two exceptions. One participant deviated from the order of inserting bone pins. The normal process is to insert one bone pin, attach the device mount to that bone pin, and then use the device mount to guide the insertion of the second bone pin. This participant inserted both bone pins and then the device mount. The participant reported that they inserted the two bone pins first because they could see existing holes in the Sawbones model. The second exception is that one participant moved the device on the device mount during registration. All other activities for all participants were successfully completed. The mean usability score was 9.03 out of $10(\mathrm{SD}=0.81)$. The estimated increase in surgical time was $6.73(\mathrm{SD}=3.71)$.

\section{Discussion}

Computer navigation in THA can improve the accuracy of acetabular cup placement, thereby improving patient outcomes and reducing revision surgeries, and yet usage remains low. Devices that combine the accuracy of imagebased systems with the speed and usability of imageless systems may help to increase the uptake of navigation in THA.

The present study assessed the accuracy that can be achieved using the inertial sensor technology that forms the basis for the INS imageless system. Using a precisely verified phantom model, the measurements from the tested devices had an overall mean absolute error of $1.21^{\circ}$ and a maximum absolute error across all devices of $4.79^{\circ}$. The mean absolute errors for the 5 tested devices were $1.34^{\circ}, 0.86^{\circ}, 1.56^{\circ}, 1.00^{\circ}, 1.30^{\circ}$, and $1.21^{\circ}$, which is clinically very small.

In the present study, the inertial navigation subsystem was isolated from the registration and surgical processes. This isolation was important for specifically assessing the baseline feasibility of using inertial sensors for navigation. The low errors suggest that this sensor technology is capable of the precision required during navigation.

Such isolated testing does not, however, include some sources of error that would be expected in actual surgery, from sources such as the surgeon, the registration process, the operating table, movement of the patient, or the alignment of the 
Table I Calibrated Phantom Angles for Each Position

\begin{tabular}{|c|c|c|c|c|}
\hline \multicolumn{3}{|c|}{ Phantom Position } & \multicolumn{2}{|c|}{ Radiographic Angle } \\
\hline Base Position & Fan Position & Shaft Position & Inclination $\left({ }^{\circ}\right)$ & Anteversion $\left({ }^{\circ}\right)$ \\
\hline 0 & 0 & $\mathrm{~N}, \mathrm{E}, \mathrm{S}, \mathrm{W}$ & 0 & 0.014 \\
\hline 0 & 2 & $\mathrm{~N}, \mathrm{E}, \mathrm{S}, \mathrm{W}$ & 0 & 30.004 \\
\hline 0 & 4 & $\mathrm{~N}, \mathrm{E}, \mathrm{S}, \mathrm{W}$ & 0 & 60.007 \\
\hline 0 & 6 & $\mathrm{~N}, \mathrm{E}, \mathrm{S}, \mathrm{W}$ & 0 & 89.903 \\
\hline 0 & 8 & $\mathrm{~N}, \mathrm{E}, \mathrm{S}, \mathrm{W}$ & 0 & II9.98I \\
\hline 0 & 10 & $\mathrm{~N}, \mathrm{E}, \mathrm{S}, \mathrm{W}$ & 0 & 149.994 \\
\hline 0 & 12 & $\mathrm{~N}, \mathrm{E}, \mathrm{S}, \mathrm{W}$ & 0 & 179.999 \\
\hline 2 & 0 & $\mathrm{~N}, \mathrm{E}, \mathrm{S}, \mathrm{W}$ & 19.9965 & 0.014 \\
\hline 2 & 2 & $\mathrm{~N}, \mathrm{E}, \mathrm{S}, \mathrm{W}$ & 19.9965 & 30.004 \\
\hline 2 & 4 & $\mathrm{~N}, \mathrm{E}, \mathrm{S}, \mathrm{W}$ & 19.9965 & 60.007 \\
\hline 2 & 6 & $\mathrm{~N}, \mathrm{E}, \mathrm{S}, \mathrm{W}$ & 19.9965 & 89.903 \\
\hline 2 & 8 & $\mathrm{~N}, \mathrm{E}, \mathrm{S}, \mathrm{W}$ & 19.9965 & | $19.98 \mid$ \\
\hline 2 & 10 & $\mathrm{~N}, \mathrm{E}, \mathrm{S}, \mathrm{W}$ & 19.9965 & 149.994 \\
\hline 2 & 12 & $\mathrm{~N}, \mathrm{E}, \mathrm{S}, \mathrm{W}$ & 19.9965 & 179.999 \\
\hline 4 & 0 & $\mathrm{~N}, \mathrm{E}, \mathrm{S}, \mathrm{W}$ & 39.9955 & 0.014 \\
\hline 4 & 2 & $\mathrm{~N}, \mathrm{E}, \mathrm{S}, \mathrm{W}$ & 39.9955 & 30.004 \\
\hline 4 & 4 & $\mathrm{~N}, \mathrm{E}, \mathrm{S}, \mathrm{W}$ & 39.9955 & 60.007 \\
\hline 4 & 6 & $\mathrm{~N}, \mathrm{E}, \mathrm{S}, \mathrm{W}$ & 39.9955 & 89.903 \\
\hline 4 & 8 & $\mathrm{~N}, \mathrm{E}, \mathrm{S}, \mathrm{W}$ & 39.9955 & II9.98I \\
\hline 4 & 10 & $\mathrm{~N}, \mathrm{E}, \mathrm{S}, \mathrm{W}$ & 39.9955 & 149.994 \\
\hline 4 & 12 & $\mathrm{~N}, \mathrm{E}, \mathrm{S}, \mathrm{W}$ & 39.9955 & 179.999 \\
\hline 6 & 0 & $\mathrm{~N}, \mathrm{E}, \mathrm{S}, \mathrm{W}$ & 59.9945 & 0.014 \\
\hline 6 & 2 & $\mathrm{~N}, \mathrm{E}, \mathrm{S}, \mathrm{W}$ & 59.9945 & 30.004 \\
\hline 6 & 4 & $\mathrm{~N}, \mathrm{E}, \mathrm{S}, \mathrm{W}$ & 59.9945 & 60.007 \\
\hline 6 & 6 & $\mathrm{~N}, \mathrm{E}, \mathrm{S}, \mathrm{W}$ & 59.9945 & 89.903 \\
\hline 6 & 8 & $\mathrm{~N}, \mathrm{E}, \mathrm{S}, \mathrm{W}$ & 59.9945 & II9.98I \\
\hline 6 & 10 & $\mathrm{~N}, \mathrm{E}, \mathrm{S}, \mathrm{W}$ & 59.9945 & 149.994 \\
\hline 6 & 12 & $\mathrm{~N}, \mathrm{E}, \mathrm{S}, \mathrm{W}$ & 59.9945 & 179.999 \\
\hline 8 & 0 & $\mathrm{~N}, \mathrm{E}, \mathrm{S}, \mathrm{W}$ & 79.996 & 0.014 \\
\hline 8 & 2 & $\mathrm{~N}, \mathrm{E}, \mathrm{S}, \mathrm{W}$ & 79.996 & 30.004 \\
\hline 8 & 4 & $\mathrm{~N}, \mathrm{E}, \mathrm{S}, \mathrm{W}$ & 79.996 & 60.007 \\
\hline 8 & 6 & $\mathrm{~N}, \mathrm{E}, \mathrm{S}, \mathrm{W}$ & 79.996 & 89.903 \\
\hline
\end{tabular}


Table I (Continued).

\begin{tabular}{|c|c|c|c|c|}
\hline \multicolumn{3}{|c|}{ Phantom Position } & \multicolumn{2}{|c|}{ Radiographic Angle } \\
\hline Base Position & Fan Position & Shaft Position & Inclination $\left({ }^{\circ}\right)$ & Anteversion $\left({ }^{\circ}\right)$ \\
\hline 8 & 8 & $\mathrm{~N}, \mathrm{E}, \mathrm{S}, \mathrm{W}$ & 79.996 & 119.981 \\
\hline 8 & 10 & $\mathrm{~N}, \mathrm{E}, \mathrm{S}, \mathrm{W}$ & 79.996 & 149.994 \\
\hline 8 & 12 & $\mathrm{~N}, \mathrm{E}, \mathrm{S}, \mathrm{W}$ & 79.996 & 179.999 \\
\hline 10 & 0 & $\mathrm{~N}, \mathrm{E}, \mathrm{S}, \mathrm{W}$ & 99.9995 & 0.014 \\
\hline 10 & 2 & $\mathrm{~N}, \mathrm{E}, \mathrm{S}, \mathrm{W}$ & 99.9995 & 30.004 \\
\hline 10 & 4 & $\mathrm{~N}, \mathrm{E}, \mathrm{S}, \mathrm{W}$ & 99.9995 & 60.007 \\
\hline 10 & 6 & $\mathrm{~N}, \mathrm{E}, \mathrm{S}, \mathrm{W}$ & 99.9995 & 89.903 \\
\hline 10 & 8 & $\mathrm{~N}, \mathrm{E}, \mathrm{S}, \mathrm{W}$ & 99.9995 & $119.98 \mid$ \\
\hline 10 & 10 & $\mathrm{~N}, \mathrm{E}, \mathrm{S}, \mathrm{W}$ & 99.9995 & 149.994 \\
\hline 10 & 12 & $\mathrm{~N}, \mathrm{E}, \mathrm{S}, \mathrm{W}$ & 99.9995 & 179.999 \\
\hline 12 & 0 & $\mathrm{~N}, \mathrm{E}, \mathrm{S}, \mathrm{W}$ & 120.0045 & 0.014 \\
\hline 12 & 2 & $\mathrm{~N}, \mathrm{E}, \mathrm{S}, \mathrm{W}$ & 120.0045 & 30.004 \\
\hline 12 & 4 & $\mathrm{~N}, \mathrm{E}, \mathrm{S}, \mathrm{W}$ & 120.0045 & 60.007 \\
\hline 12 & 6 & $\mathrm{~N}, \mathrm{E}, \mathrm{S}, \mathrm{W}$ & 120.0045 & 89.903 \\
\hline 12 & 8 & $\mathrm{~N}, \mathrm{E}, \mathrm{S}, \mathrm{W}$ & 120.0045 & 119.981 \\
\hline 12 & 10 & $\mathrm{~N}, \mathrm{E}, \mathrm{S}, \mathrm{W}$ & 120.0045 & 149.994 \\
\hline 12 & 12 & $\mathrm{~N}, \mathrm{E}, \mathrm{S}, \mathrm{W}$ & 120.0045 & 179.999 \\
\hline 14 & 0 & $\mathrm{~N}, \mathrm{E}, \mathrm{S}, \mathrm{W}$ & 140.004 & 0.014 \\
\hline 14 & 2 & $\mathrm{~N}, \mathrm{E}, \mathrm{S}, \mathrm{W}$ & 140.004 & 30.004 \\
\hline 14 & 4 & $\mathrm{~N}, \mathrm{E}, \mathrm{S}, \mathrm{W}$ & 140.004 & 60.007 \\
\hline 14 & 6 & $\mathrm{~N}, \mathrm{E}, \mathrm{S}, \mathrm{W}$ & 140.004 & 89.903 \\
\hline 14 & 8 & $\mathrm{~N}, \mathrm{E}, \mathrm{S}, \mathrm{W}$ & 140.004 & II9.98| \\
\hline 14 & 10 & $\mathrm{~N}, \mathrm{E}, \mathrm{S}, \mathrm{W}$ & 140.004 & 149.994 \\
\hline 14 & 12 & $\mathrm{~N}, \mathrm{E}, \mathrm{S}, \mathrm{W}$ & 140.004 & 179.999 \\
\hline 16 & 0 & $\mathrm{~N}, \mathrm{E}, \mathrm{S}, \mathrm{W}$ & 160.0005 & 0.014 \\
\hline 16 & 2 & $\mathrm{~N}, \mathrm{E}, \mathrm{S}, \mathrm{W}$ & 160.0005 & 30.004 \\
\hline 16 & 4 & $\mathrm{~N}, \mathrm{E}, \mathrm{S}, \mathrm{W}$ & 160.0005 & 60.007 \\
\hline 16 & 6 & $\mathrm{~N}, \mathrm{E}, \mathrm{S}, \mathrm{W}$ & 160.0005 & 89.903 \\
\hline 16 & 8 & $\mathrm{~N}, \mathrm{E}, \mathrm{S}, \mathrm{W}$ & 160.0005 & II9.98| \\
\hline 16 & 10 & $\mathrm{~N}, \mathrm{E}, \mathrm{S}, \mathrm{W}$ & 160.0005 & I 49.994 \\
\hline 16 & 12 & $\mathrm{~N}, \mathrm{E}, \mathrm{S}, \mathrm{W}$ & 160.0005 & 179.999 \\
\hline
\end{tabular}

Notes: The radiographic inclination and anteversion angles were determined using a high-precision coordinate measuring machine (CMM). Radiographic inclination was represented by rotation around the base. Radiographic anteversion was represented by rotation around the fan. These verified angles were taken to represent the true angles. 

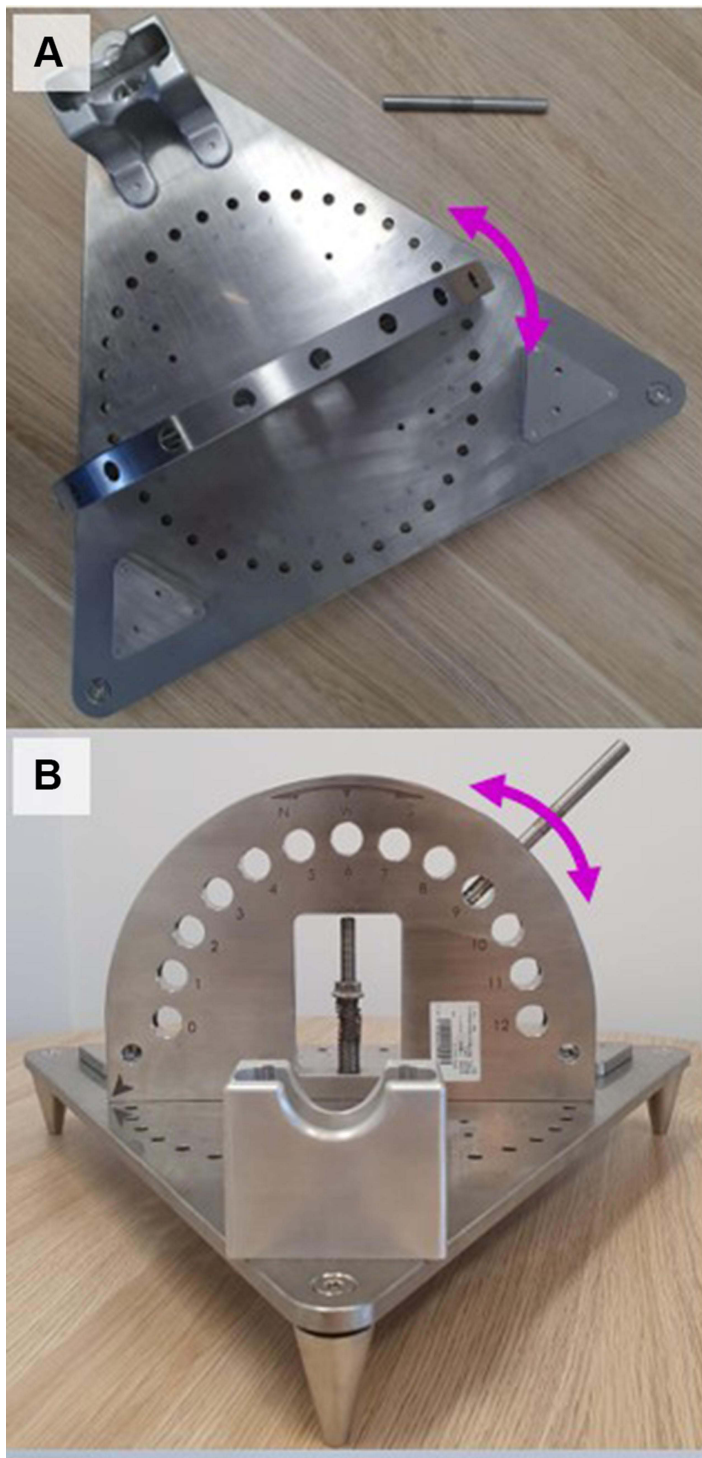

\section{C}

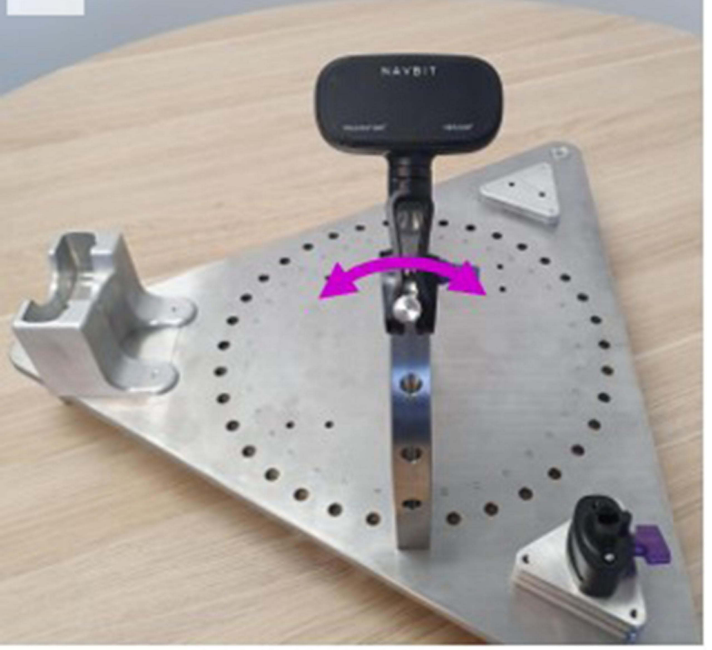

Figure 8 Testing process.

Notes: Each measurement occurred at specified base position (A), fan position (B), and device rotation (C). 
Table 2 Accuracy Testing Results

\begin{tabular}{|l|l|l|l|l|l|}
\hline & \multicolumn{5}{|c|}{ Device } \\
\hline & $\mathbf{I}$ & $\mathbf{2}$ & $\mathbf{3}$ & $\mathbf{4}$ & $\mathbf{5}$ \\
\hline Mean absolute error $\left({ }^{\circ}\right)$ & 1.34 & 0.86 & 1.56 & 1.00 & 1.30 \\
\hline Standard deviation of absolute error $\left({ }^{\circ}\right)$ & 0.84 & 0.52 & 0.76 & 0.49 & 0.60 \\
\hline Upper 95\% Cl of absolute error $\left({ }^{\circ}\right)$ & 1.54 & 0.99 & 1.75 & 1.13 & 1.44 \\
\hline Maximum absolute error $\left({ }^{\circ}\right)$ & 4.79 & 2.40 & 3.69 & 3.20 & 2.69 \\
\hline
\end{tabular}

Note: For each device, the statistics were calculated using the absolute error at each of 250 device orientations.

Abbreviation: $\mathrm{Cl}$, confidence interval.

devices. The cadaver study by Shatrov et $\mathrm{al}^{24}$ included all of these potential sources of error. Under those circumstances, the resulting error of the device was somewhat increased ( $1.88^{\circ}$ for inclination and $3.70^{\circ}$ for anteversion). Thus, this INS technology is still capable of accurate results when it is included in the broader registration and surgical processes.

With respect to the usability testing, after watching a simple training video, in $99 \%$ of cases, the surgeons completed the tasks correctly. This suggests that the device, instructions, and training were adequate in most cases. It appeared that the simulated setting (and existing holes in a Sawbones model) caused the error relating to the order of the insertion of the bone pins. If this error were to happen in surgery, there could be additional pressure on bone pins while attaching the device mount, but device accuracy would not be affected as long as the device mount was securely attached. The rating of the usability was high (9/10) and the estimated increase in surgical time was low (7 minutes). Taken together, these results suggest that the system is usable and fast to use.

Overall, the INS technology is capable of accurate intraoperative measurements, and the system is fast and easy-touse.

\section{Conclusion}

The Navbit Sprint ${ }^{\circledR}$ is an accurate, fast, and usable imageless navigation device that provides the surgeon with real-time acetabular cup inclination and anteversion angles during THA, with minimal impact on the surgical time.

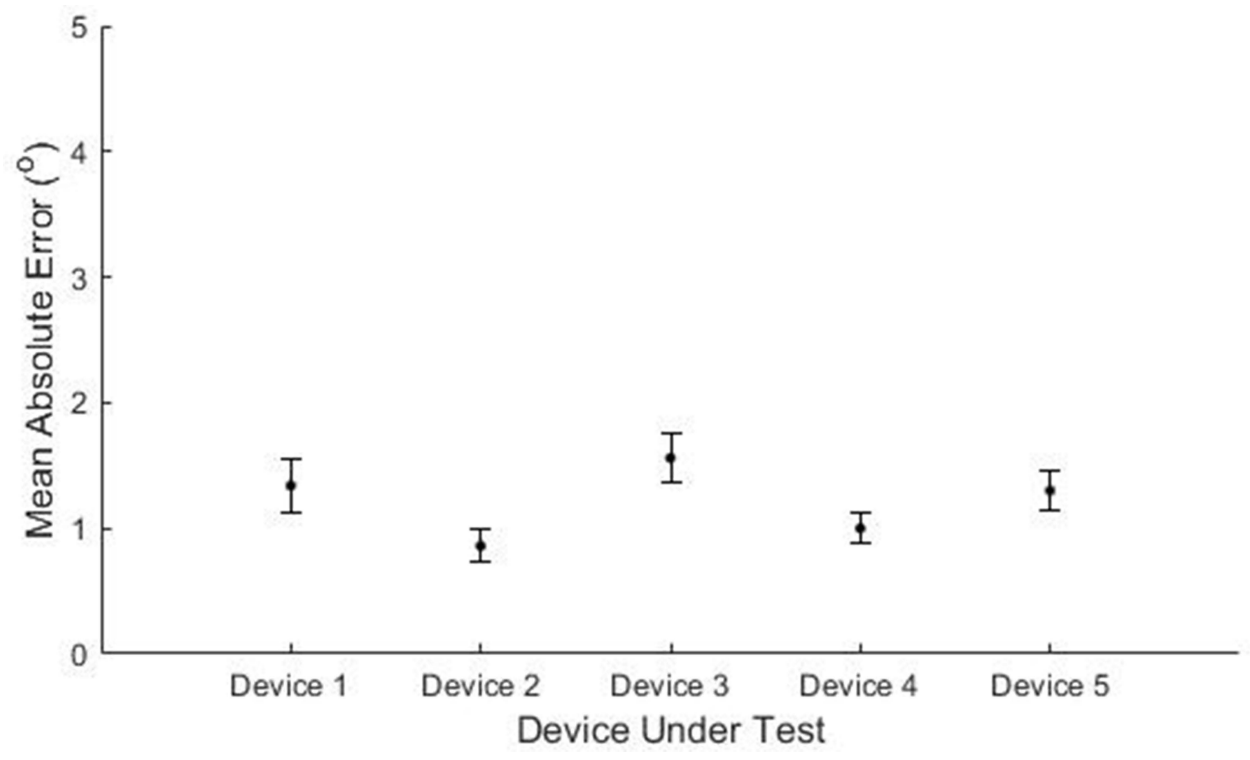

Figure 9 Accuracy of Navbit Sprint Navigation System.

Note: The mean absolute error of each device is shown with the $95 \%$ confidence interval. 


\section{Disclosure}

William L Walter receives consulting/royalty payments from JJ DePuy and Matortho, he is a shareholder in 360 and Navbit and is a board member for the Institute of Bone and Joint Research. In addition, Professor William L Walter has a patent 8790278 issued to Silesco, a patent 10463415 issued to Navbit. Neri A Baker, Ameneh Sadeghpour, and Daniel Marsden-Jones are employees of Navbit. Daniel Marsden-Jones has a patent 2021900293 pending to Navbit. The authors report no other conflicts of interest in this work.

\section{References}

1. Learmonth ID, Young C, Rorabeck C. The operation of the century: total hip replacement. Lancet. 2007;370(9597):1508-1519. doi:10.1016/S01406736(07)60457-7

2. Bozic KJ, Kurtz SM, Lau E, Ong K, Vail TP, Berry DJ. The epidemiology of revision total hip arthroplasty in the United States. J Bone Joint Surg Am. 2009;91(1):128-133. doi:10.2106/JBJS.H.00155

3. Masaoka T, Yamamoto K, Shishido T, et al. Study of hip joint dislocation after total hip arthroplasty. Int Orthop. 2006;30(1):26-30. doi:10.1007/ s00264-005-0032-4

4. Werner BC, Brown TE. Instability after total hip arthroplasty. World J Orthop. 2012;3(8):122-130. doi:10.5312/wjo.v3.i8.122

5. D'lima DD, Urquhart AG, Buehler KO, Walker RH, Colwell CW Jr. The effect of the orientation of the acetabular and femoral components on the range of motion of the hip at different head-neck ratios. J Bone Joint Surg Am. 2000;82(3):315-321. doi:10.2106/00004623-20000300000003

6. Widmer KH. Containment versus impingement: finding a compromise for cup placement in total hip arthroplasty. Int Orthop. 2007;31(Suppl1): S29-33. doi:10.1007/s00264-007-0429-3

7. Widmer KH, Zurfluh B. Compliant positioning of total hip components for optimal range of motion. J Orthop Res. 2004;22(4):815-821. doi:10.1016/j.orthres.2003.11.001

8. DeWal H, Su E, DiCesare PE. Instability following total hip arthroplasty. Am J Orthop. 2003;32(8):377-382.

9. Jolles BM, Zangger P, Leyvraz PF. Factors predisposing to dislocation after primary total hip arthroplasty: a multivariate analysis. $J$ Arthroplasty. 2002;17(3):282-288. doi:10.1054/arth.2002.30286

10. Patil S, Bergula A, Chen PC, Colwell CW Jr, D'lima DD. Polyethylene wear and acetabular component orientation. J Bone Joint Surg Am. 2003;85-A(Suppl 4):56-63. doi:10.2106/00004623-200300004-00007

11. Novikov D, Mercuri JJ, Schwarzkopf R, Long WJ, Bosco Iii JA, Vigdorchik JM. Can some early revision total hip arthroplasties be avoided? Bone Joint J. 2019;101-B(6_Supple_B):97-103. doi:10.1302/0301-620X.101B6.BJJ-2018-1448.R1

12. Wasterlain AS, Buzar JA, Thakkar SC, Schwarzkopf R, Vigdorchik J. Navigation and robotics in total hip arthroplasty. JBJS Rev. $2017 ; 5(3): 1$. doi:10.2106/JBJS.RVW.16.00046

13. Gandhi R, Marchie A, Farrokhyar F, Mahomed N. Computer navigation in total hip replacement: a meta-analysis. Int Orthop. 2009;33(3):593-597. doi:10.1007/s00264-008-0539-6

14. Xu K, Li Y-M, Zhang H-F, Wang C-G, Xu Y-Q, Li Z-J. Computer navigation in total hip arthroplasty: a meta-analysis of randomized controlled trials. Int J Surg. 2014;12(5):528-533. doi:10.1016/j.ijsu.2014.02.014

15. Li Y-L, Jia J, Wu Q, Ning G-Z, Wu Q-L, Feng S-Q. Evidence-based computer-navigated total hip arthroplasty: an updated analysis of randomized controlled trials. Eur J Orthop Surg Traumatol. 2014;24(4):531-538. doi:10.1007/s00590-013-1222-1

16. Agarwal S, Eckhard L, Walter WL, et al. The use of computer navigation in total hip arthroplasty is associated with a reduced rate of revision for dislocation: a study of 6912 navigated THA procedures from the Australian Orthopaedic Association National Joint Replacement Registry. JBJS. 2021;103(17). doi:10.2106/JBJS.2120.00950

17. Bohl DD, Nolte MT, Ong K, Lau E, Calkins TE, Della Valle CJ. Computer-assisted navigation is associated with reductions in the rates of dislocation and acetabular component revision following primary total hip arthroplasty. J Bone Joint Surg Am. 2019;101(3):250-256. doi:10.2106/ JBJS.18.00108

18. Christ A, Ponzio D, Pitta M, Carroll K, Muir JM, Sculco PK. Minimal increase in total hip arthroplasty surgical procedural time with the use of a novel surgical navigation tool. Open Orthop J. 2018;12:389-395.doi:10.2174/1874325001812010389

19. Kreuzer S, Leffers K. Direct anterior approach to total hip arthroplasty using computer navigation. Bull NYU Hosp Joint Dis. 2011;69(Suppl 1): S52-55.

20. Snijders T, Gaalen SM, Gast A. Precision and accuracy of imageless navigation versus freehand implantation of total hip arthroplasty: a systematic review and meta-analysis. Int J Med Robot. 2017;13(4):e1843-n/a. doi:10.1002/rcs.1843

21. Davenport D, Kavarthapu V. Computer navigation of the acetabular component in total hip arthroplasty: a narrative review. EFORT Open Rev. 2016;1(7):279-285. doi:10.1302/2058-5241.1.000050

22. Lin FD, Lim DP, Wixson RLMD, Milos SMD, Hendrix RWMD, Makhsous MP. Limitations of imageless computer-assisted navigation for total hip arthroplasty. J Arthroplasty. 2011;26(4):596-605. doi:10.1016/j.arth.2010.05.027

23. Feng JE, Anoushiravani AA, Eftekhary N, Wiznia D, Schwarzkopf R, Vigdorchik JM. Techniques for optimizing acetabular component positioning in total hip arthroplasty: defining a patient-specific functional safe zone. JBJS Rev. 2019;7(2):e5.

24. Shatrov J, Marsden-Jones D, Lyons M, Walter WL. Improving acetabular component positioning in total hip arthroplasty: a cadaveric study of an inertial navigation tool and a novel registration method. HSS J. 2021:15563316211051727. doi:10.1177/15563316211051727

25. Murray DW. The definition and measurement of acetabular orientation. J Bone Joint Surg. 1993;75(2):228-232. doi:10.1302/0301620X.75B2.8444942

26. Gurgel HMCP, Croci ATP, Cabrita HABAP, Vicente JRNP, Leonhardt MC, Rodrigues JC. Acetabular component positioning in total hip arthroplasty with and without a computer-assisted system: a Prospective, Randomized and Controlled Study. J Arthroplasty. 2014;29 (1):167-171. doi:10.1016/j.arth.2013.04.017 
27. Davis ET, Schubert M, Wegner M, Haimerl M. A new method of registration in navigated hip arthroplasty without the need to register the anterior pelvic plane. J Arthroplasty. 2015;30(1):55-60. doi:10.1016/j.arth.2014.08.026

28. Lass R, Kubista B, Olischar B, Frantal S, Windhager R, Giurea A. Total hip arthroplasty using imageless computer-assisted hip navigation A Prospective Randomized Study. J Arthroplasty. 2014;29(4):786-791. doi:10.1016/j.arth.2013.08.020

29. Sendtner E, Schuster T, Wörner M, Kalteis T, Grifka J, Renkawitz T. Accuracy of acetabular cup placement in computer-assisted, minimally-invasive THR in a lateral decubitus position. Int Orthop. 2011;35(6):809-815. doi:10.1007/s00264-010-1042-4

30. Wan Z, Malik A, Jaramaz B, Chao L, Dorr LD. Imaging and navigation measurement of acetabular component position in THA. Clin Orthop Relat Res. 2009;467(1):32-42. doi:10.1007/s11999-008-0597-5

31. Cross MB, Schwarzkopf R, Miller TT, Bogner EA, Muir JM, Vigdorchik JM. Improving registration accuracy during total hip arthroplasty: a cadaver study of a new, 3-D mini-optical navigation system. Hip Int. 2018;28(1):33-39. doi:10.5301/hipint.5000533

\section{Publish your work in this journal}

Medical Devices: Evidence and Research is an international, peer-reviewed, open access journal that focuses on the evidence, technology, research, and expert opinion supporting the use and application of medical devices in the diagnosis, monitoring, treatment and management of clinical conditions and physiological processes. The identification of novel devices and optimal use of existing devices which will lead to improved clinical outcomes and more effective patient management and safety is a key feature of the journal. The manuscript management system is completely online and includes a very quick and fair peer-review system. Visit http://www.dovepress.com/testimonials.php to read real quotes from published authors.

Submit your manuscript here: https://www.dovepress.com/medical-devices-evidence-and-research-journal 